\section{Sedation with mida- zolam during regional anaesthesia: is there a role for flumazenil?}

Liam Claffey MD, Gilles Plourde MSc MD,

Joan Morris, BSc MHSc, ${ }^{*}$ Michel Trahan BSc, Deanne M. Dean PhD*
The aim of this study was to reassess the efficacy of flumazenil for reversal of sedation with midazolam. Twenty-four ASA I or II patients undergoing elective surgery under epidural anaesthesia participated. Following epidural block, midazolam was administered to keep the patient sleepy but still responsive to verbal commands. At the end of surgery the patients were randomly allocated to receive, in a double-blind manner, either flumazenil $\left(0.1 \mathrm{mg} \cdot \mathrm{ml}^{-1}\right)$ or placebo. The study drug (maximum dose: $10 \mathrm{ml}$ ) was titrated until the patient became fully awake. Sedation was assessed with the Modified Steward Coma Scale (MSCS), the Trieger test (TT) and Critical Flicker Frequency (CFF). The assessments were done before anaesthesia (baseline), at the end of surgery immediately before administration of study drug, and serially afterwards, at 10,30,60, $90,120,150$ and $180 \mathrm{~min}$. Analyses of variance for repeated measures and pooled t tests were used. The duration of surgery was (mean $\pm S D$ ) $0.72 \pm 0.25 \mathrm{hr}$ in the flumazenil group and $0.74 \pm 0.28 \mathrm{hr}$ in the placebo group. The total dose of midazolam was $7.2 \pm 2.2 \mathrm{mg}$ for the flumazenil group and $8.9 \pm 2.7 \mathrm{mg}$ for the placebo group. The volume of study drug administered was $5.5 \mathrm{ml} \pm 1.9$, equivalent to $0.55 \mathrm{mg}$, for the flumazenil group and $6.7 \pm 2.2 \mathrm{ml}$ for the placebo group. Critical Flicker Frequency is the only measure which revealed a difference $(P<0.005)$ between the flumazenil and

\section{Key words}

ANAESTHETIC TECHNIQUES: epidural; HYPNOTIC: benzodiazepines; midazolam; MEASUREMENT TECHNIQUES: critical flicker frequency, Trieger test.

From the Departments of Anaesthesia, Royal Victoria Hospital and McGill University, Montreal (Quebec) Canada and *Hoffmann-La Roche Ltd., Toronto, Ontario, Canada.

These results were presented in part at the Annual Meeting of the Canadian Anaesthetists' Society held in Quebec City in June, 1991 (Reference 1).

Address correspondence to: Dr. Gilles Plourde, Department of Anaesthesia, Royal Victoria Hospital, 687 Pine Avenue West, Suite S5.05, Montreal, Quebec, Canada H3A IA1. Accepted for publication 22nd July, 1994 placebo groups and this occurred only at the ten-minute assessment. We conclude that flumazenil is rarely needed when midazolam is titrated to provide light sedation during regional anaesthesia. The spontaneous recovery from midazolam is fast enough.

Cette étude vise à réévaluer l'efficacité antagoniste du flumazénil sur la sédation au midazolam. Vingt-quatre patients $A S A$ I et II soumis à une chinurgie élective sous anesthésie épidurale font partie de l'étude. Après le bloc épidural, le midazolam est administré de façon à maintenir le patient assoupi mais toujours apte à répondre à un ordre verbal. $A$ la fin de la chirurgie, les patients sont répartis au hasard pour recevoir à double aveugle soit du flumazénil $\left(0,1 \mathrm{mg} \cdot \mathrm{ml}^{-1}\right)$ soit un placebo. Le produit à l'étude (dose maximale: $10 \mathrm{ml}$ ) est titré jusqu'au réveil complet. La sédation est évaluée sur l'échelle modifiée de Steward pour le coma, le test de Trieger et le test de fréquence critique de fusion. Les évaluations sont réalisées avant l'anesthésie (ligne de base), à la fin de la chirurgie immédiatement avant l'administration du produit à l'étude, et séquentiellement par la suite à 10,30,60,90,120,150 et 180 min. Des analyses de variance pour mesures répétées et des tests de Student regroupés sont utilisés. La durée de la chirurgie est de (moyenne $\pm S D$ ) $0,72 h \pm 0,25$ pour le groupe flumazénil et de 0,74 $\pm 0,28 \mathrm{~h}$ pour le groupe placebo. La dose totale de midazolam est de 7,2 $\pm 2.2 \mathrm{mg}$ pour le groupe flumazénil et de $8,9 \pm 2,7 \mathrm{mg}$ pour le groupe placebo. Le volume administré du produit à létude est de $5,5 \pm 1,9 \mathrm{ml}$ (équivalence $0,55 \mathrm{mg}$ ), pour le groupe flumazénil, et de 6,7 $\pm 2,2 \mathrm{ml}$ pour le groupe placebo. Le test de fréquence de fusion est la seule mesure qui révèle une différence $(P<0,005)$ entre les groupes flumazénil et placebo et cette différence n'apparaît qu'à l'étape dix minutes. Nous concluons qu'on a rarement besoin de flumazénil lorsque le midazolam est titré pour produire une sédation légère pendant l'anesthésie régionale, la récupération spontanée après midazolam étant suffisamment rapide.

Benzodiazepines are frequently used during regional anaesthesia to reduce anxiety, provide sedation and amnesia. Of the available benzodiazepines, midazolam offers the fastest recovery. Flumazenil is an imidazobenzodiaze- 
pine that blocks the central effects of benzodiazepines by competitive interaction at the receptor site. It is capable of reversing the behavioural, neurological and electrophysiological effects of all benzodiazepine agonists. ${ }^{2}$ One obvious question is whether there is a role for flumazenil in reversing the residual effects of midazolam used to provide light sedation during regional anaesthesia. A number of studies have examined the use of flumazenil for reversal of midazolam sedation. Funtan et al. ${ }^{3}$ Ricou et al. ${ }^{4}$ (elderly subjects) and Bianchi and Stenier ${ }^{5}$ showed that flumazenil speeds recovery. These studies, however, included a heavy premedication with oral or intramuscular midazolam. Rubin and Rocke ${ }^{6}$ also included a heavy premedication with midazolam, but found that spontaneous recovery occurred so rapidly that flumazenil would rarely be needed.

Four studies have examined the use of flumazenil for reversal of midazolam sedation without premedication. Rodrigo et al. ${ }^{7}$ found that a fixed dose, $0.5 \mathrm{mg}$, of flumazenil, given after short, $15 \mathrm{~min}$, dental procedures markedly reduced the time for recovery from midazolam, average dose $6.2 \mathrm{mg}$, compared with placebo. Ochs et al. ${ }^{8}$ reported similar findings with $0.8 \mathrm{mg}$, average dose, of flumazenil given following a large dose, $0.27 \mathrm{mg} \cdot \mathrm{kg}^{-1}$, of midazolam for presumably short dental procedures. The beneficial effects of flumazenil lasted $60 \mathrm{~min}$. Likewise, a US multicentre study ${ }^{9}$ found that $0.72 \mathrm{mg}$ of flumazenil, average dose, following a mean dose of 10 $\mathrm{mg}$ of midazolam for procedures lasting $\mathbf{4 0} \mathrm{min}$ on average clearly enhanced the speed of recovery during the first $60 \mathrm{~min}$. By contrast, Kestin et al. ${ }^{10}$ found that a fixed dose, $0.5 \mathrm{mg}$, of flumazenil provided only incomplete and brief reversal of the effects of low doses of midazolam, $0.07-0.08 \mathrm{mg} \cdot \mathrm{kg}^{-1}$, for procedures lasting $46 \mathrm{~min}$ on average. One suspects that, for the studies of Rodrigo et al. and Ochs et al., the beneficial effects of flumazenil were due to a somewhat heavy dose of midazolam, combined with short procedures. With moderate sedation (e.g., the US Multicenter Study), flumazenil still had a clear effect. The modest effect of flumazenil observed by Kestin et al. ${ }^{10}$ may be ascribed to light sedation or insufficient amount of flumazenil.

The aim of this double-blind, randomized placebocontrolled study was to re-assess the efficacy of flumazenil in reversing the effects of midazolam used for sedation during regional anaesthesia. We have used three measures of recovery: (1) the modified Steward Coma Scale (MSCS) ${ }^{11}$; (2) the Trieger Dot Test ${ }^{12}$; and (3) the Critical Flicker Frequency (CFF) Test. ${ }^{13-16}$ Like Kestin et al. ${ }^{10}$ we aimed for light sedation. Midazolam was titrated to have patients who, when not disturbed, stayed quiet with their eyes closed but who remained responsive to verbal commands. However, we did not use a fixed dose of
TABLE I Modified Steward coma scale

\begin{tabular}{lr}
\hline Consciousness & 4 \\
Fully awake, eyes open conversive & 3 \\
Lightly asleep, eyes open intermittently & 2 \\
Eyes open on command or in response to name & 1 \\
Responding to ear pinching & 0 \\
Not responding & 3 \\
Airway & 2 \\
Opening mouth and/or coughing on command & 1 \\
No voluntary cough, but airway clear without support & 0 \\
Airway obstructed on neck flexion but clear without support & \\
on extension & \\
Airway obstructed without support & 2 \\
Activity & 1 \\
Raising one arm on command & 0 \\
Non-purposeful movement & \\
Not moving &
\end{tabular}

antagonist. Instead, flumazenil was titrated to a maximum of one mg.

\section{Methods}

\section{Patients}

Twenty-four ASA I-II patients, four women, aged 18-55 $y r$, and scheduled to undergo peripheral surgery under regional anaesthesia, were consecutively enroled after approval by the Ethics Committee. Each patient gave written consent. Patients with any of the following were excluded: pregnancy, benzodiazepine allergy, recent (two weeks) or long-term benzodiazepine use, epilepsy, excessive consumption of alcohol, $\geq$ four drinks per week, or caffeine, $\geq$ four cups of coffee daily. The patients were randomly allocated to either flumazenil, 12 patients, or placebo 12 patients, in a double-blind manner. One patient from the flumazenil group could not complete the assessments in the Recovery Room, because the epidural block was too high and caused arm weakness. The patient was excluded from analysis and replaced by another patient. There were, therefore, 12 patients in each group.

\section{Assessment of sedation}

All procedures were explained to the patient in detail. Ample time was available for practice before baseline recordings. The patients were always assessed in a semireclining position. The Modified Steward Coma Scale (MSCS), adapted from reference 11, is described in Table I.

\section{TRIEGER TEST}

The Trieger Test ${ }^{12}$ is an adaptation of the Bender-Gestalt test. ${ }^{17}$ For the Trieger Test, the subject is shown a simple design made of dots $9-10 \mathrm{~mm}$ apart and is asked to 
join the dots with a pencil. The performance is assessed by counting the number of dots missed and by measuring the total distance between the missed dots and the line drawn by the patient. The time taken to complete the task is also recorded. Patients with refractive error wore their spectacles for all assessments.

\section{CRITICAL FLICKER FREQUENCY (CFF)}

The CFF is the threshold frequency at which a flashing light is perceived to be constant. It provides a simple, quantitative and sensitive measure of central nervous system impairment. ${ }^{13-16}$ It was measured using a custombuilt signal generator, incorporating goggles with a builtin light emitting diode, which presented a flickering red light (diameter $=4 \mathrm{~mm}$ ) (wavelength $660 \mathrm{~nm}$ ) to the patient's dominant eye. The other eye was occluded with an opaque goggle. The mean luminous intensity was 2.6 millicandelae (mcd) for all tests. To produce flicker, instantaneous luminous intensity oscillated between $\mathbf{0}$ and 5.2 mcd (mean intensity $\pm 100 \%$ ) according to a sinusoidal waveform. The CFF was assessed with the method of limits. (Although the method of forced choice is preferable in principle ${ }^{18}$ both methods yield comparable results. The present work was done before the work described in reference 18.) For each trial, the flicker frequency (number of cycles per second) was initially 50 $\mathrm{Hz}$ and decreased at the rate of $1.3 \mathrm{~Hz} \cdot \mathrm{sec}^{-1}$ to $30 \mathrm{~Hz}$. The patients were asked to press a hand-held button as soon as they perceived flicker. The frequency at which this occurred was recorded, and the procedure was repeated at least three times for each assessment. The average of these measures was used for scoring.

When the patient failed to perform the test because of excessive sedation, a score of $30 \mathrm{~Hz}$ was arbitrarily assigned. This was necessary because even a single missing value results in exclusion of the patient in a repeated measures design. Pilot tests showed that $30 \mathrm{~Hz}$ was the lowest value that could be reliably measured in heavily sedated patients.

Because drugs often change pupillary diameter (and secondarily retinal illuminance, which influences $\mathrm{CFF},{ }^{14}$ ) the pupillary diameter was measured before determination of the CFF, and analysis of covariance was used to determine whether or not changes in pupillary diameter could account for the CFF changes.

\section{Anaesthesia and procedures}

The patients were not premedicated. Baseline measures of the MSCS, CFF and Trieger tests were obtained 30 min before entering the operating room. After insertion of a large bore $i v$ cannula, the ECG electrodes, blood pressure cuff and pulse oximeter probes were attached. Epidural anaesthesia, using an indwelling catheter, was
TABLE II Sedation scale used to guide the administration of midazolam and flumazenil placebo (adapted from Kestin et al. ${ }^{19}$ )

$5=$ Awake, tense

$4=$ Awake, not tense

$3=$ Drowsy

$2=$ Sleepy, verbally arousable

$1=$ Sleepy, arousable with mild physical stimulation

$0=$ Not arousable with mild physical stimulation

provided with carbonated lidocaine, $2.2 \% ; 10-20 \mathrm{ml}$, with epinephrine, $5 \mu \mathrm{g} \cdot \mathrm{ml}^{-1}$.

When the block was established, midazolam, 30 $\mu \mathrm{g} \cdot \mathrm{kg}^{-1}$ was given $\dot{i}$. Increments of midazolam of 7.5 $\mu \mathrm{g} \cdot \mathrm{kg}^{-1}$ were administered as needed at two-minute intervals, until the patient was sleepy but easily arousable with verbal commands (Level 2 on the sedation score of Table II). This level of sedation was maintained until completion of the surgical procedure, by increments of midazolam of $7.5 \mu \mathrm{g} \cdot \mathrm{kg}^{-1}$. At the end of surgery the MSCS was recorded, and the patient, still on the operating table, was tilted to the semi-sitting position before performing the CFF and Trieger tests. These were the "pre-study drug" or time 0 assessments.

Flumazenil, $0.1 \mathrm{mg} \cdot \mathrm{ml}^{-1}$, or placebo, both supplied by Hoffmann-LaRoche, was administered at the rate of $2 \mathrm{ml}$ initially over $20 \mathrm{sec}$, followed by $20 \mathrm{sec}$ of observation and assignment of a sedation score. Further doses of $1 \mathrm{ml}$ were given at each minute, until the patient was awake but not tense, sedation Score 4 on Table II, or until $10 \mathrm{ml}$ of solution had been given. Ten minutes after the beginning of the study drug administration, the MSCS was recorded, and the patients performed the CFF and Trieger tests. The patient was then moved to a quiet recovery area, where normal nursing care was provided. The MSCS, CFF and Trieger tests were recorded every $30 \mathrm{~min}$ until three hours after the commencement of the administration of flumazenil or placebo, time 0 . Patients were then discharged home or to the ward. All scoring was done by the same person.

Pain was controlled in the Recovery Room area by epidural injections of bupivacaine, $0.25 \%$. The Recovery Room staff was informed about the study and was asked to inform us about any symptoms or problems. The patients were seen or contacted by telephone $24 \mathrm{hr}$ postoperatively to inquire about pain at the injection site.

\section{Statistics}

All procedures ${ }^{19}$ were performed by J.C. Baskerville, and L.W. Stitt, of Statlab (University of Western Ontario, London, Ontario). For each outcome variable, the change from the pre-study drug assessment (time 0 ) was calculated. The measures were thereby automatically adjusted for possible differences in baseline levels between fluma- 
TABLE III Mean (SD)

\begin{tabular}{lll}
\hline & Flumazenil & Placebo \\
\hline Number of men-women & $10-2$ & $10-2$ \\
Age (yr) & $40.7(6.9)$ & $30.4(7.1)^{*}$ \\
Height $(\mathrm{cm})$ & $174(9)$ & $177(8)$ \\
Weight $(\mathrm{kg})$ & $77.9(11.3)$ & $76.5(9.9)$ \\
Duration of surgery (hr) & $0.72(0.25)$ & $0.75(0.28)$ \\
Total dose of midazolam (mg) & $7.2(2.2)$ & $8.9(2.7)$ \\
Volume of study drug (m) & $5.5(1.9)$ & $6.7(2.2)$ \\
\hline
\end{tabular}

$* P<0.01$.

zenil and placebo groups. Analysis of variance (ANOVAs) for repeated measures were used to assess the effect of drug (flumazenil versus placebo), time (repeated factor, seven assessments) and time-drug interaction. Greenhouse-Geisser adjustment of the significance levels were used. The level for significance was $P<0.05$ for the ANOVAs. T tests, based on the pooled estimate of variance, derived from the ANOVAs, were used to compare flumazenil versus placebo at each assessment, $\mathrm{t}=$ $10,30,60,90,120,150$ and $180 \mathrm{~min}$ after study drug administration. The level of significance was $P<0.007$ for the pooled $t$ tests, in order to obtain an overall error rate of 0.05 (Bonferonni correction). Analysis of covariance was used to examine (1) the effect of the age difference between the flumazenil and placebo group; (2) the contribution of pupillary size to CFF changes. Unpaired $\mathrm{t}$ tests were used to compare the characteristics of the flumazenil versus placebo group. Level of significance was $P<0.05$ for these $t$ tests.

\section{Results}

Demographic data, duration of surgery and doses of midazolam and study drug are given in Table III. There was an age difference between the flumazenil and placebo groups $(P<0.01)$. To investigate the effect of this imbalance, all comparisons between flumazenil and placebo were performed both with and without age as a covariate. Because age never had any noticeable effect, the results of the analysis without age as a covariate are given. For the other variables, the difference between the flumazenil and placebo groups did not approach significance.

\section{Modified Stewart coma scale (MSCS)}

There was a slightly greater increase for the flumazenil group at ten and $30 \mathrm{~min}$ after treatment (Figure 1). The differences did not reach significance $(P<0.03$ and $P$ $<0.08$ respectively). The ANOVA yielded no significant effects.

Trieger dot test - number of dots missed

Patients in the flumazenil group missed more dots than

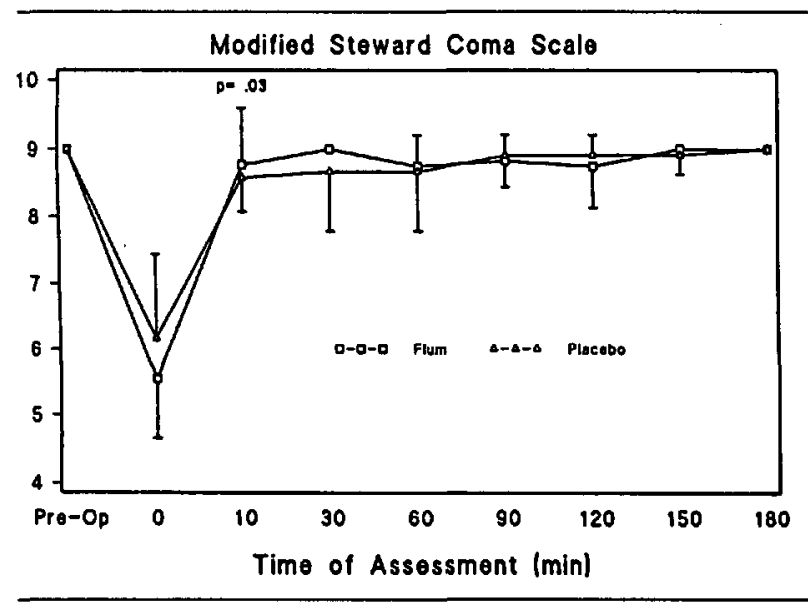

FIGURE I Modified Steward coma scale. The bars indicate standard deviation in this and all other figures. The absence of a bar for some data points indicates that the standard deviation was too small to be represented. The time scale is not linear for the first four assessments (Pre-op to $30 \mathrm{~min}$ ).

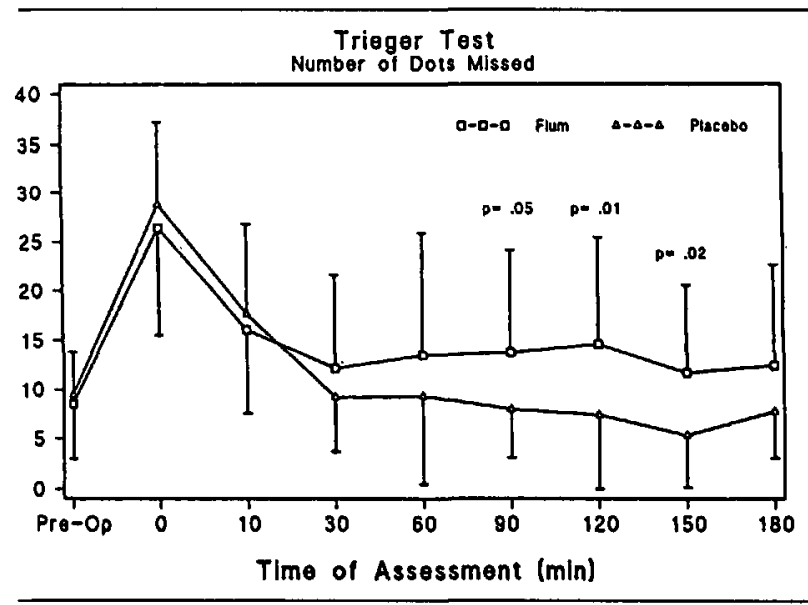

FIGURE 2 Trieger test - number of dots missed.

those in the placebo group from 30 to $180 \mathrm{~min}$ after treatment (Figure 2). The greatest differences occurred between 90 and $150 \mathrm{~min}$ after treatment and nearly reached significance ( $P$ ranged from 0.01 to 0.05$)$. The ANOVA yielded drug $(P<0.04)$ and time $(P<0.001)$ effects without significant interaction.

Trieger dot test - total deviations from dots

The total deviation from the dots was larger for patients in the flumazenil group from 30 to $180 \mathrm{~min}$ after treatment (Figure 3), but the differences did not reach significance. The ANOVA yielded a time effect $(P<0.001)$ but no drug effect or interaction.

Trieger dot test - completion times

Patients who had received flumazenil were faster than 


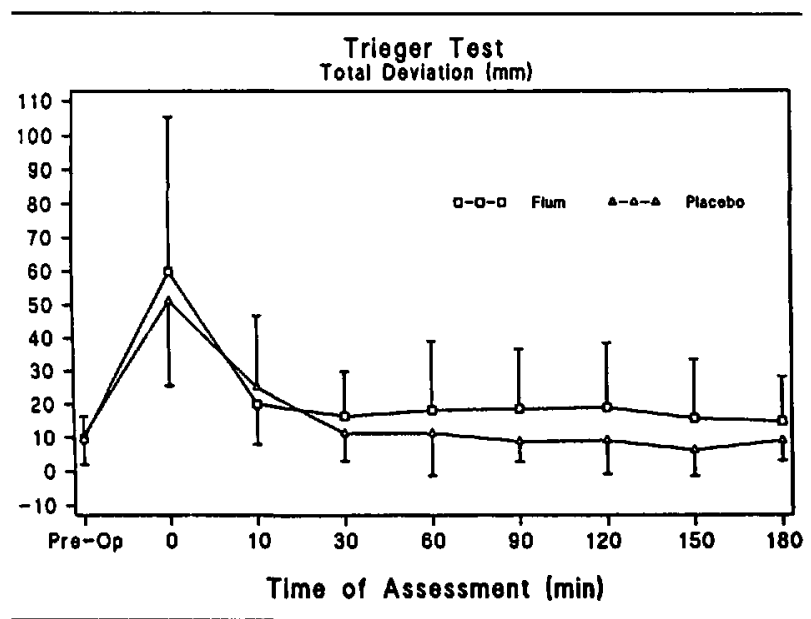

FIGURE 3 Trieger test - total deviation.

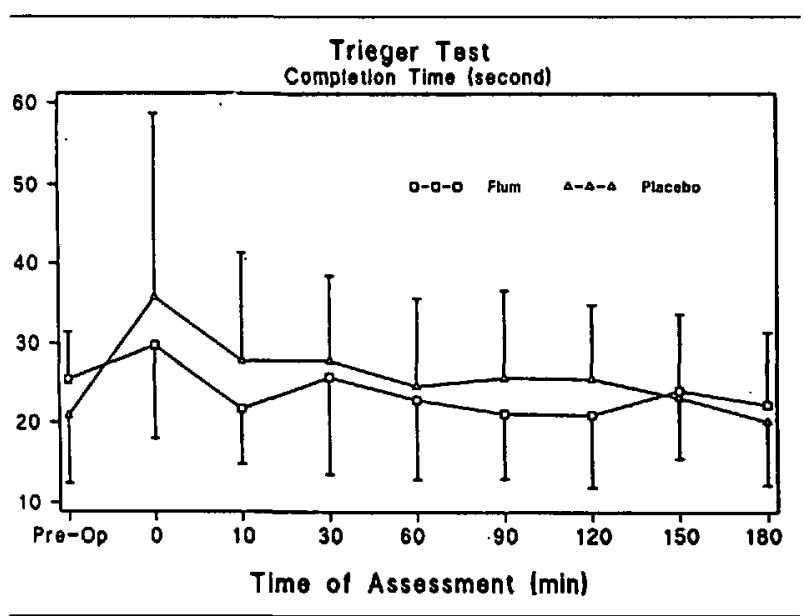

FIGURE 4 Trieger test - completion time.

the placebo group from ten to $120 \mathrm{~min}$ after treatment (Figure 4). To investigate the effect of this difference, the completion time was entered as a time-varying covariate for both the number of dots missed and the total deviation from dots. There was a negative correlation $(P<0.001)$ between completion times and the number of dots missed, but the effects of drug and time, noted above, remained significant. There was also a similar negative correlation $(P<0.001)$ between completion times and total deviation from dots. The effect of time, noted above, remained significant.

\section{Critical flicker frequency}

Patients in the flumazenil group showed a higher frequency than the placebo group at ten minutes after treatment $(P<0.005)$ (Figure 5). The differences between the two groups from 30 to $180 \mathrm{~min}$ after treatment did not approach significance. The ANOVA yielded no drug effect but there was an effect of time $(P<0.01)$. There

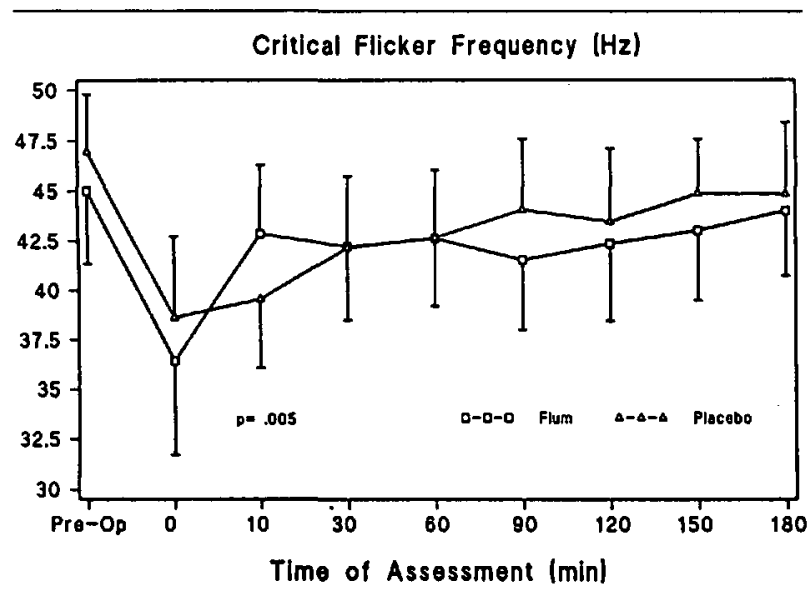

FIGURE 5 Critical flicker frequency.

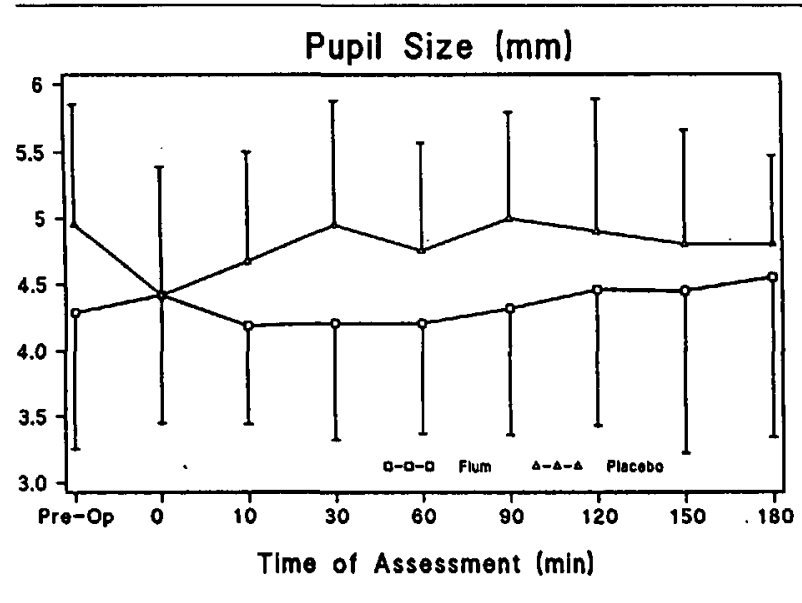

FIGURE 6 Pupil size.

was an interaction $(P<0.01)$ between drug and time, indicating that the pattern of CFF increase following study drug administration was different between flumazenil and placebo.

Mean pupillary diameter was larger for the placebo group at baselinē (pre-op) and during all subsequent measures except time 0 , when there was no difference (Figure 6). Using pupil size as a time-varying covariate revealed no effect of pupillary diameter on the analysis of the CFF results.

\section{Adverse events}

Five patients experienced adverse events in the three hours following administration of the study drug. They all belonged to the placebo group. One patient had syncope upon standing up at three hours, two patients complained of transient dizziness, one patient was transiently confused, and one patient had hiccoughs. Syncope was treated with atropine, $0.4 \mathrm{mg} i v$. The other adverse events 
resolved rapidly without treatment. At the $24 \mathrm{hr}$ assessment, one patient from the flumazenil group complained of mild to moderate pain at the injection site. No patients from the placebo group complained of pain at the injection site.

\section{Discussion}

The Critical Flicker Frequency results at ten minutes provided the only evidence that recovery was faster in the flumazenil group. The Modified Steward Coma Scale also revealed a faster recovery in the flumazenil group at ten minutes, but the difference was small and did not reach significance. By contrast, the Trieger Test (number of dots missed) revealed a better performance in the placebo group from 30 to $180 \mathrm{~min}$ after treatment. The differences nearly reached significance between 90 and $150 \mathrm{~min}$ after treatment. A possible explanation for this unexpected finding is that patients of the flumazenil group were more alert and had better memory. They would accordingly have become bored with the highly repetitive Trieger Test.

The average dose of midazolam in the present study is slightly higher than that of the Kestin et al. ${ }^{10}$ study but slightly smaller than that of the US multicentre study. ${ }^{9}$ The average dose of flumazenil given in the present study $(0.55 \mathrm{mg})$ is almost the same as the fixed dose of $0.5 \mathrm{mg}$ used by Kestin et al. ${ }^{10}$ but is less than the average dose reported in the US Multicenter Study, 0.72 $\mathrm{mg} .{ }^{9}$ The duration of surgery is almost the same for the three studies. Like Kestin et al., we could only demonstrate a weak and transient reversal of midazolam effects by flumazenil, presumably because of the rapid spontaneous recovery from midazolam.

The US multicentre study ${ }^{9}$ demonstrated a clear effect of flumazenil for $60 \mathrm{~min}$ whereas our results revealed only a weak and transient effect. A possible explanation is that, at the end of surgery, the patients of the US Study were more heavily sedated than were our patients. The mean Observer's Assessment of Alertness/Sedation Scale $(\mathrm{OAA} / \mathrm{S})^{20}$ was 3 in the US Study, indicating that the patients responded only to loud or repeated verbal commands, or had slurred speed or marked jaw relaxation or marked palpebral ptosis. The intended level of sedation in our study was to keep the patient sleepy yet easily arousable verbally (probably corresponding to an $\mathrm{OAA} / \mathrm{S}$ score of 2). The sedative end point is not specified in the US multicentre study.

Our results cannot be compared with those of Rodrigo et al. ${ }^{7}$ because there is a three-fold difference in the duration of surgery ( $45 \mathrm{~min}$ vs $15 \mathrm{~min}$ ). Likewise, it is difficult to compare our results with those of Ochs et al. ${ }^{8}$ because they used a much larger dose of midazolam.

The small, transient effect of flumazenil observed in the present study cannot be explained by lack of sensitivity of the measures used to assess recovery. Critical Flicker Frequency test is so sensitive that neither the placebo nor the flumazenil group had returned to baseline after three hours (Figure 5).

We conclude that flumazenil is rarely needed when midazolam is titrated to provide light sedation during regional anaesthesia. The spontaneous recovery from midazolam is fast enough.

\section{Acknowledgements}

This study was supported by a grant from Hoffman-La Roche Limited. We thank J. Faubert for sharing his knowledge of CFF determinations; P. April for building the CFF device, E. Dionisopoulos and S. Caney for typing the manuscript.

\section{References}

1 Claffey L, Plourde G, Trahan M, Morris J, Dean DM. Flumazenil for reversal of sedation with midazolam during regional anaesthesia. Can J Anaesth 1991; 38: A6.

2 Geller E, Halpern $P$. Benzodiazepine antagonists. Int Anesthesiol Clin 1991; 29: 69-81.

3 Funtan E, Lupolover $R$, Allen $S R$. Flumazenil (Ro 15-1788) for reversal of midazolam-induced sedation in regional anaesthesia. Eur J Anaesthesiol 1988; 2: 219-32.

4 Ricou B, Forster A, Brïckner A, Chastonay P, Gemperle $M$. Clinical evaluation of a specific benzodiazepine antagonist (RO 15-1788). Br J Anaesth 1986; 58: 1005-11.

5 Bianchi $G$, Stenier $P$. A clinical double-blind study of flumazenil, antagonist of benzodiazepines, in loco-regional anesthesia. Acta Anaesthesiol Belg 1992; 43: 121-9.

6 Rubin J, Rocke DA. Reversal of low-dose midazolam sedation with flumazenil (Ro 15-1788) following urological surgery under spinal anaesthesia. Eur J Anaesthesiol 1988; Suppl. 2: 229-32.

7 Rodrigo MRC, Chan L, Hui E. Flumazenil reversal of conscious sedation for minor oral surgery. Anaesth Intensive Care 1992; 20: 174-6.

8 Ochs $M W$, Tucker MR, Owsley TG, Anderson JA. The effectiveness of flumazenil in reversing the sedation and amnesia produced by intravenous midazolam. J Oral Maxillafac Surg 1990; 48: 240-245.

9 The Flumazenil in Intravenous Conscious Sedation with Midazolam Multicenter Study Group I. Reversal of central nervous system effects by flumazenil after intravenous conscious sedation with midazolam: report of a multicenter clinical study. Clin Ther 1992; 14: 861-77.

10 Kestin IG, Harvey PB, Nixon C. Psychomotor recovery after three methods of sedation during spinal anaesthesia. Br J Anaesth 1990; 64: 675-81.

11 Robertson GS, MacGregor DM, Jones CJ. Evaluation of 
doxapram for arousal from general anaesthesia in outpatients. Br J Anaesth 1977; 49: 133-9.

12 Newman $M G$, Trieger $N$, Miller JC. Measuring recovery from anesthesia - a simple test. Anesth Analg 1969; 48: 136-40.

13 Simonson $E$, Brožek $J$. Flicker fusion frequency. Background and applications. Physiol Rev 1952; 32: 349-78.

14 Brown $J L$. Flicker and intermittent stimulation. In: Graham $\mathrm{CH}$ (Ed.). Vision and Visual Perception. New York: John Wiley \& Sons, Inc. 1965: 251-320.

15 Smith $J M$, Misiak $H$. Critical flicker frequency (CFF) and psychotropic drugs in normal human subjects - a review. Psychopharmacology (Berl) 1976; 47: 175-82.

16 Wesnes $K$, Simpson P, Christmas $L$. The assessment of human information-processing abilities in psychopharmacology. Human Psychopharmacology 1987; 1: 79-92.

17 Lezak MD. Neuropsychological Assessment. New York: Oxford University Press, 1976.

18 Salib Y, Plourde G, Alloul K, Provost A, Moore A. Measuring recovery from general anaesthesia using critical flicker frequency: a comparison of two methods. Can J Anaesth 1992; 39: 1045-50.

19 Kirk RE. Experimental Design: Procedures for the Behavioural Sciences, 2nd ed. California: Brooks/Cole Publishing Company, 1982.

20 Chernik DA, Gillings $D$, Laine $H$, et al. Validity and reliability of the observer's assessment of alertness/sedation scale: study with intravenous midazolam. J Clin Psychopharmacol 1990; 10: 244-51. 